\title{
Comparison between first-born and second-born children regarding prevalence of narcissistic traits: an appraisal of adler's conjecture
}

\begin{abstract}
Introduction: Adlerian theory suggests that birth order and the number of siblings affect a child's behaviour. In the present assessment, the prevalence of narcissistic traits has been compared between first-born and second born children to assess once more the aforementioned claim.

Method: Six hundreds parents, among the clienteles to a medical clinic, had been asked, randomly and sequentially, to determine that which one of the traits of the narcissistic personality disorder, according to the DSM-5's diagnostic criteria, could be accounted as a distinguished characteristic of their first or second children.

Result: All of the narcissistic personality traits, except one ("Is interpersonally exploitative ") were significantly more prevalent among first-born children $(p<0.05)$. Conjectural narcissistic personality disorder (with at least five traits), too was significantly more prevalent among the first-born children in comparison with the second-born children $(\mathrm{p}<0.05)$, which was as well significantly more prevalent in male participants of the associated group $(\mathrm{p}<0.05)$.
\end{abstract}

Conclusion: it seems that the first-born children show higher chance for acquiring narcissistic personality traits in comparison with the second-born children; an outcome in support of substantial role of nurture.

Keywords: birth order, narcissism, narcissistic personality traits, narcissistic personality disorder, personality development
Volume 4 Issue 3 - 2017

\author{
Saeed Shoja Shafti \\ University of Social Welfare and Rehabilitation Sciences, Razi \\ Psychiatric Hospital, Iran
}

Correspondence: Saeed Shoja Shafti,Associate Professor of Psychiatry, University of Social Welfare and Rehabilitation Sciences (USWR), Razi Psychiatric Hospital, Tehran, Iran, Postal code: 18669-5889|, Po Box: 18735-569, Tel 0098-2|-3340|220, Fax 0098-21-33401604,Email ssshafti@gmail.com

Received: October 30, 2016 | Published: December 28, 2017

\section{Introduction}

The study of human personality or 'character' dates back at leas to antiquity. In his 'Characters', Tyrtamus (371-287bc) - nicknamed 'Theophrastus' or 'divinely speaking' by his contemporary Aristotle divided the people of the Athens into 30 different personality types. The 'Characters' exerted a strong influence on subsequent studies of human personality such as those of Thomas Overbury (1581-1613) in England and Jean de la Bruy è re (1645-1696) in France. ${ }^{1}$ According to Jung, "Personality is the supreme realization of the innate idiosyncrasy of a living being. It is an act of high courage flung in the face of life, the absolute affirmation of all that constitutes the individual, the most successful adaption to the universal conditions of existence coupled with the greatest possible freedom for self- determination." Also, according to Kierkegaard, "being an individual man is a thing that has been abolished, and every speculative philosopher confuses himself with humanity at large; whereby he becomes something infinitely great, and at the same time nothing at all. To be a particular individual is world-historically absolutely nothing, infinitely nothing - and yet, this is the only true and highest significance of a human being, so much higher as to make every other significance illusory". ${ }^{1}$

Alfred Adler was the first to develop a comprehensive theory of personality, psychological disorders and psychotherapy, which represented an alternative to the views of Freud. ${ }^{2}$ One facet of his complex body of work involves the importance of birth order for youth outcomes. Adlerian theory suggests that birth order and the number of siblings affect a child's behavior. ${ }^{3}$ Since then different modalities of personality and human behaviors became the focus of research which included intelligence, achievements, mental ability, sexual orientation, etc., ${ }^{4,5}$ However, few studies have specifically examined the effect of birth order on young adult mental health, and the results of most of the birth order studies are contradictory and unsystematized. ${ }^{6,7}$ As a result, some of the critics believe that: "although researchers have examined the effects of birth order on intelligence, achievement, and personality, many of these studies have insuperable flaws, and they have produced weak or inconsistent results". Contrary to these findings, Sulloway claims that birth order has been criticized unfairly due largely to methodological issues. ${ }^{9}$ In his book Born to Rebel, Frank Sulloway suggests that birth order has strong and consistent effects on the Big Five personality traits (Openness, Conscientiousness, Extraversion, Agreeableness, and Neuroticism). He argues that first-borns are more conscientious, more socially dominant, less agreeable, and less open to new ideas compared to later-born. ${ }^{9}$ However, critics such as Fred Townsend, Toni Falbo, and Judith Rich Harris, argue against Sulloway's theories. For example, in their book Sibling Relationships: Their Nature and Significance across the Lifespan, Michael E. Lamb and Brian Sutton-Smith make the point that sibling relationships often last an entire lifetime, and all relationships change over time, and any effects of birth order may be eliminated, reinforced, or altered by later experiences. ${ }^{10}$

Anyhow, while the influence of siblings on the socialization of the individual has been recognized as a fact by psychology and sociology, 9,11 the significance of sibling order for the outbreak of psychiatric diseases is still discussed controversially. For instance, while in a metanalysis, Polit and Falbo found that first-born, only children, and children with one other sibling score higher on tests of verbal ability than later-born and children with multiple siblings; ${ }^{12}$ such a result was not persistently reproducible because recent studies have suggested that past researches have focused too heavily on early life and there is ,in addition, a distinctly higher rate of success among 
second borns later in life in the areas of career as well as wealth. ${ }^{13}$ Alternatively, in another study significant difference was found between first-born and last-born participants with respect to weekly drinks and binge frequencies. Also, last-borns reported a higher risk for alcohol-related behaviors than first-borns. ${ }^{14}$ Similarly, according to a study in Chile, being the first born male was a protective factor against substance use. This was also true for first born females. But For educational outcomes, birth order showed no significance. ${ }^{15}$ Then over again, in a survey to study the association between birth order and development of psychopathology, it was found that depression and alcohol dependence was the commonest diagnosis in adult group, irrespective of birth order. ${ }^{16}$ Moreover, regarding the connection between birth order and narcissism, there are a few studies that show that such a relationship is in essence obvious. ${ }^{17,18}$ Based on the above-mentioned inconsistencies, in the present study, once more, the relationship between birth order and narcissistic personality traits, as has been described in the Diagnostic and Statistical Manual of mental disorders, $5^{\text {th }}$ edition (DSM-5), ${ }^{19}$ has been evaluated.

\section{Methods}

Six hundred parents, among the clienteles to a medical clinic, had been asked, randomly and sequentially, by a trained staff, after Table I Prevalence of narcissistic personality traits and other related issues among participant children

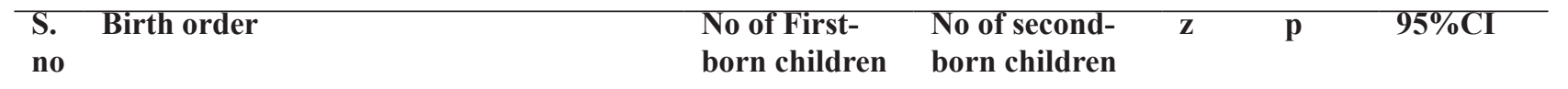

\begin{tabular}{|c|c|c|c|c|c|c|}
\hline & Narcissistic traits & & & & & \\
\hline 1 & Has a grandiose sense of self-importance & 288 & 240 & 2.79 & 0.005 & $0.02,0.13$ \\
\hline 2 & $\begin{array}{l}\text { Is preoccupied with fantasies of unlimited } \\
\text { success, power, brilliance, naughty, or ideal } \\
\text { love }\end{array}$ & 294 & 192 & 5.99 & 0 & $0.11,0.22$ \\
\hline 3 & $\begin{array}{l}\text { Believes that he or she is special and unique } \\
\text { and can only be understood by, or should } \\
\text { associate with, other special or high status } \\
\text { people }\end{array}$ & 228 & 180 & 2.92 & 0.003 & $0.02,0.13$ \\
\hline 4 & Requires excessive admiration & 294 & 246 & 2.78 & 0.005 & $0.02,0.13$ \\
\hline 5 & Has a sense of entitlement & 282 & 228 & 3.15 & 0.001 & $0.03,0.14$ \\
\hline 6 & Is interpersonally exploitative & 234 & 246 & -0.7 & 0.479 & $-0.07,0.03$ \\
\hline 7 & Lacks empathy & 234 & 180 & 3.27 & 0.001 & $0.03,0.14$ \\
\hline 8 & $\begin{array}{l}\text { Is often envious of others or believes that } \\
\text { others are envious to him or her }\end{array}$ & 204 & 126 & 5.04 & 0 & $0.07,0.18$ \\
\hline 9 & $\begin{array}{l}\text { Shows arrogant, haughty behaviors or } \\
\text { attitudes }\end{array}$ & 204 & 120 & 5.46 & 0 & $0.08,0.19$ \\
\hline 10 & $\begin{array}{l}\text { Conjectural Narcissistic Personality } \\
\text { Disorder (with at least } 5 \text { traits) }\end{array}$ & 246 & 162 & 5.11 & 0 & $0.08,0.19$ \\
\hline 11 & More dominant & 276 & 234 & 2.45 & 0.014 & $0.01,0.12$ \\
\hline 12 & More submissive & 216 & 246 & -1.77 & 0.075 & $-0.10,0.00$ \\
\hline 13 & More successful & 282 & 288 & -0.34 & 0.728 & $-0.06,0.04$ \\
\hline 14 & More satisfied & 276 & 300 & -1.38 & 0.165 & $-0.09,0.01$ \\
\hline
\end{tabular}

description of the procedure for them, to determine that which trait of the narcissistic personality disorder, according to the DSM-5, could be accounted as a distinguished characteristic of their first or second children. The aforesaid items had been printed as a questionnaire, and the parents replay was recorded as positive only if these items could be distinguished as an ordinary, not infrequent, behavior of the children. Only families with children older than 14 years old had been included in this study and the families with only one child or children younger than 14 years old had been excluded. It was accentuated that this comparison was taking place only between the first and second children, disregard to the remaining offspring. Therefore if, for example, one of their children, whether first or second, had been died previously, then no symbolic replacement or rearrangement in the order of children was acceptable according to the inclusion criteria of the present assessment and that family had been excluded and replaced by another family. In addition to the aforesaid intentions, four additional questions also were added to the questionnaire. These were general questions regarding to the 'submissiveness', dominance', 'achievement ' and 'contentment' of their first or second children (Table 1). As a final point, each child with at least five narcissistic traits was acknowledged, theoretically, as narcissistic personality disorder. 


\section{Statistical analysis}

Data were analyzed by $\mathrm{Z}$ test for assessment of equality of proportions. The statistical significance was defined as $\mathrm{P}$ value equal or less that 0.05. MedCalc Statistical Software version 15.2 was used as statistical software tool for analysis.

\section{Results}

Demographic characteristics of the children have been represented in Table 2. The number of male and female participants was comparable, in both of the first-born and second-born children. According to the findings, the $6^{\text {th }}$ trait, "Is interpersonally exploitative", was reversely and non-significantly more common in the second-borne children in our sample $(p<0.47)$ (Table 1, Figure 1). But the other traits such as: " Has a grandiose sense of self-importance" , "Is preoccupied with fantasies of unlimited success, power, brilliance, naughty, or ideal love"," believes that he or she is special and unique and can only be understood by, or should associate with, other special or high status people", "Requires excessive admiration", "Has a sense of entitlement", "lacks empathy", "Is often envious of others or believes that others are envious to him or her" , "Shows arrogant, haughty behaviors or attitudes" were significantly more prevalent among first-borne children $(\mathrm{p}<0.005, \mathrm{p}<0.00, \mathrm{p}<0.0034, \mathrm{p}<0.005, \mathrm{p}<0.001$, $\mathrm{p}<0.001, \mathrm{p}<0.000$ and $\mathrm{p}<0.00$, respectively) (Table 1, Figure 1). Conjectural narcissistic personality disorder (with at least five traits), too, was significantly more prevalent among the first-born children in comparison with the second -born children $(\mathrm{p}<0.00)$ (Figure 2), which was as well significantly more prevalent in male participants of the associated group $(\mathrm{p}<0.00)$ (Table 3 ). Moreover and according to the findings, although first-born children showed significantly more "Dominant" pattern of behaviour in comparison with the secondborn children $(p<0.01)$, but that was not so regarding the items of "more submissive" ( $p<0.07)$, "more successful" $(p<0.72)$ and "more satisfied" $(\mathrm{p}<0.16)$.

Table 2 Demographic characteristics of participant children

\begin{tabular}{lllllll}
\hline Birth order & Male & Female & $\mathbf{z}$ & $\mathbf{P}$ & $\mathbf{9 5 \%} \mathbf{C l}$ & Total \\
\hline No of First-born children & 312 & 288 & 1.38 & 0.16 & $-0.01,0.09$ & 600 \\
No of Second-born children & 309 & 291 & 1.03 & 0.29 & $-0.02,0.08$ & 600 \\
Total & 621 & 579 & 1.71 & 0.08 & $-0.005,0.070$ & 1200 \\
\hline
\end{tabular}

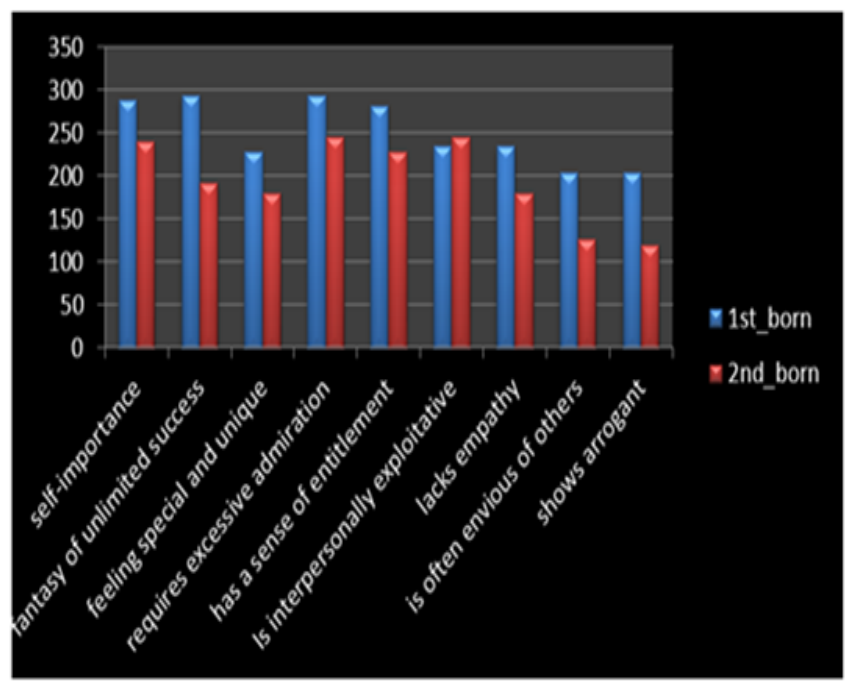

Figure I Comparison of narcissistic personality traits between first-born and second-born children.

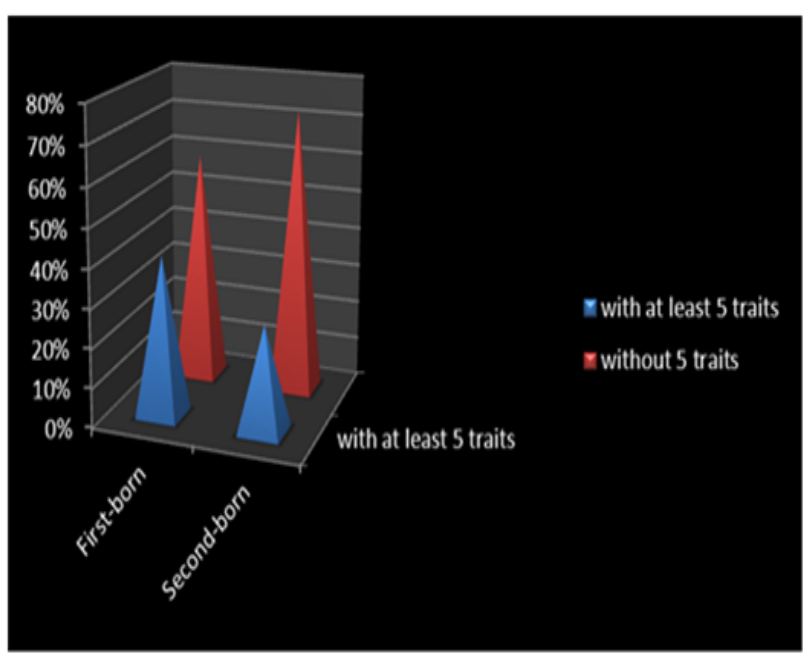

Figure 2 Comparison of conjectural narcissistic personality disorder (with at least five traits) between first-born and second-born children.

Table 3 Gender-based comparison of conjectural narcissistic personality disorder (with at least five traits) between first-born and second-born children

\begin{tabular}{|c|c|c|c|c|c|c|}
\hline Birth order & Male & Female & $\mathbf{z}$ & $\mathbf{P}$ & $95 \% \mathrm{Cl}$ & Total \\
\hline No of First-born children with at least five traits & 156 & 90 & 4.71 & 0 & $0.06,0.15$ & 246 \\
\hline No of Second-born children With at least five traits & 84 & 78 & 0.5 & 0.61 & $-0.02,0.04$ & 162 \\
\hline
\end{tabular}

\section{Discussion}

The essential feature of narcissistic personality disorder is a pervasive pattern of grandiosity, need for admiration, and lack of empathy that begins by early adulthood and is present in a variety of contexts. Individuals with this disorder have a grandiose sense of self-importance (Criterion 1) ${ }^{19}$ They routinely overestimate their abilities and inflate their accomplishments, often appearing boastful and pretentious. Individuals with narcissistic personality disorder are often preoccupied with fantasies of unlimited success, power, brilliance, beauty, or ideal love (Criterion 2). Prevalence estimates for narcissistic personality disorder, based on DSM-IV definitions, range from $0 \%$ to $6.2 \%$ in community samples. Narcissistic traits may be particularly common in adolescents and do not necessarily indicate that the individual will go on to have narcissistic personality disorder. 
Of those diagnosed with narcissistic personality disorder, $50 \%-75 \%$ are male. ${ }^{19}$ Perspective of Adler on the subject of birth order denotes that patients need to be understood in the context of their family environments, and child's position in the family can be associated with the induction or consolidation of certain characters, a phenomenon that is comparable with the relationship between social position of an adult person and his or her expectations or decisions. Besides, Adler had stressed that it was not the numerical birth position itself that was concretely important, but rather the situation and advantages accompanying that position and the child's reaction to them was the determining agent with respect to the future character. Anyhow, since the significance of birth order on behalf of youth outcomes and child's ultimate behaviour have been the center of attention, thus basic developmental processes have been persistently the focus of research and analyses. For example, the results of a cross-tabulation analysis found that earlier-born participants held more favourable images of God than later-born participants, a difference that may be affected by their early childhood experiences within the family. ${ }^{20}$ Also, according to another study, birth order effects were statistically significant on two constructs: problem-solving persistence and joy. Larger family size related to lower life satisfaction and attention to emotions. ${ }^{21}$ Also, According to a series of studies, main effects of birth order and gender are significant in the process of separation-individuation, ${ }^{22}$ identity formation, ${ }^{23}$ and Basic Competence Test (BCT) scores, ${ }^{24}$ and that the only child is less autonomous than the oldest child. ${ }^{22}$ Our findings, also, are in harmony with some of the preceding studies, which had found high correlation between narcissism and first-born children, based on Narcissistic Personality Inventory ${ }^{17}$ and higher mean scores on the measures of pathological narcissism, based on The Millon Clinical Multiaxial Inventory and the Narcissistic Personality Inventory, in first-born and only children. ${ }^{18}$ Also more significant frequency of supposed NPD among male participants in the present assessment was in harmony with the prevalence rate that has been declared by DSM5. Alder's viewpoint concerning the influence of birth order on the configuration of personality of child was one of the foremost historical hints in the sphere of developmental psychology. He described the first child as jealous who does not want to share its benefits with the next ones and the second child as one who must tirelessly strive to compete with the first sibling for saving its advantages. This description of affairs is very alike to the kind of interaction between narcissistic and non-narcissistic people. Findings of the present study, as like as the earlier ones, are in favour of existence of further chance for absorption of such kind of characters by the first- borne children vis-àvis the second- borne ones. So, nurture maybe is more imperative than nature in configuration of personality. This is a useful standpoint that accentuates again on the role of parenting and environmental factors on establishment of the character. But while here first-born children with at least five narcissistic traits were significantly more than the second- born ones, no significant difference was evident between them with respect to achievement and satisfaction in life. Hence, mere constellation of traits does not seem to be enough to bring into being morbid tension, except than in accompanies with special state of affairs. Small sample size, limitation of research to a middle-class urban area, lack of standardized and innovative outcome measures, absence of extra sources or direct observation for verification of data and particularly relying on parent's subjective judgment were among the weak points of this assessment. Further large practical randomized, well-designed, appraisals are necessary to evaluate the relative effects of birth order on development of human character.

\section{Conclusion}

It seems that the first-born children show higher chance for acquiring narcissistic personality traits in comparison with the secondborn children; an outcome in support of substantial role of nurture.

\section{Acknowledgements}

The author gratefully acknowledges dear colleagues, Hashemi J $(\mathrm{PhD})$, Jahanpoor P (MS), and the department of research for their practical and financial support of this study.

\section{Conflict of interest}

The author declares no conflict of interest.

\section{References}

1. Burton N. Psychiatry. 2nd ed. UK: Wiley-Blackwell; 2010. 240 p.

2. Adler A, Philip Mairet, Heinz Ludwig Ansbacher. Problems of neurosis. Harper and Row, New York, USA; 1964. 180 p.

3. Stewart AE, Eckstein D. Birth Order within Individual Psychology. Journal of Individual Psychology. 2012;68:1 p.

4. Eckstein Dl, Kaufman JA. The Role of Birth Order in Personality: An Enduring Intellectual Legacy of Alfred Adler. Journal of Individual Psychology. 2012;68(1):60-74.

5. Stewart AE. Issues in Birth Order Research Methodology: Perspectives from Individual Psychology. Journal of Individual Psychology. 2012;68(1):75 p.

6. Conley JJ. Family configuration as an etiological factor in alcoholism. $J$ Abnorm Psychol. 1980;89(5):670-673.

7. Falbo T. Only Children: An Updated Review. Journal of Individual Psychology. 2012;68(1):38-49.

8. Freese J, Powell B. Review of Frank J Sulloway's Born to Rebel: Birth Order, Family Dynamics, and Creative Lives. Contemporary Sociology. 1998;27:57-58.

9. Sulloway FJ. Birth Order, Sibling Competition, and Human Behaviour. Conceptual Challenges in Evolutionary Psychology. 2001;39-83.

10. Lamb ME, Sutton SB. Sibling Relationships: Their Nature and Significance of the Lifespan. New Jersey: Lawrence Erlbaum Associates; $1982.416 \mathrm{p}$.

11. Chakraborty A. Birth order and mental illness. Br J Soc Psychiat. 1969;3(4):231-236

12. Polit DF, Falbo T. The intellectual achievement of only children. $J$ Biosoc Sci. 1998;20(3):275-285.

13. Rodgers JL, Cleveland HH, van den Oord E, et al. Resolving the debate over birth order, family size, and intelligence. Am Psychol. 2000;55(6):599-612.

14. Laird TG, Shelton AJ. From an Adlerian Perspective: Birth Order, Dependency, and Binge Drinking on a Historically Black University Campus. Journal of Individual Psychology. 2006;62(1):18-35.

15. Horner P, Andrade F, Delva J, et al. The Relationship of Birth Order and Gender with Academic Standing and Substance Use Among Youth in Latin America. J Individ Psychol. 2012;68(1):19-37.

16. Risal A, Tharoor H. Birth order and psychopathology. J Family Med Prim Care. 2012;1(2):137-140. 
17. Eyring WE, Sobelman S. Narcissism and birth order. Psychol Rep 1996;78(2):403-406.

18. Curtis JM, Cowell DR. Relation of birth order and scores on measures of pathological narcissism. Psychol Rep. 1993;72(1):311-315.

19. Diagnostic and Statistical Manual of Mental Disorders. 5th ed. USA American Psychiatric Association; 2013. 970 p.

20. Hui-Tzu Grace Chou, Britani Liska. Effects of Birth Order on an Individual's Image of God within a White, Mormon Sample. Journal of Individual Psychology. 2013;69(2):143-155.

21. Khodarahimi S, Ogletree SL. Birth Order, Family Size, and Positive Psychological Constructs: What Roles Do They Play for Iranian Adolescents and Young Adults? Journal of Individual Psychology. 2011;67(1):41-56.
22. Byrd B, DeRosa AP, Craig SS. The adult who is an only child: achieving separation or individuation. Psychol Rep. 1993;73(1):171-177.

23. Wong TM, Branje SJ, VanderValk IE, et al. The role of siblings in identity development in adolescence and emerging adulthood. J Adolesc. 2010;33(5):673-682.

24. Cheng CC, Wang WL, Sung YT, et al. Effect modification by parental education on the associations of birth order and gender with learning achievement in adolescents. Child Care Health Dev. 2013;39(6):894 902. 